\title{
A INTERAÇÃO E COOPERAÇÃ̃ NO SETOR DE TIC EM BUSCA DA INOVAÇÃO: UMA COMPARAÇÃO ENTRE OS POLOS DE COIMBRA E DE CURITIBA
}

Pollyanna Rodrigues Gondin ${ }^{1}$

Walter Tadahiro Shima ${ }^{2}$

Nuno Teles ${ }^{3}$

\begin{abstract}
RESUMO: Este trabalho tem como objetivo analisar como a interação e a cooperação, tanto formal quanto informal, entre empresas e instituições pertencentes as aglomerações de empresas de Tecnologia da Informação e Comunicação (TIC), em Curitiba (Brasil) e em Coimbra (Portugal), atuam como fator-chave para que a inovação ocorra. A partir da análise da teoria e das entrevistas realizadas, pretende-se comparar os dois polos, bem como as diversas formas de interação que ocorrem neles, verificando como potenciam a transferência de conhecimento e aprendizado entre os agentes. Ao mesmo tempo, busca-se verificar a dinâmica inovativa específica de cada aglomeração no contexto local, tendo como base, também, a dinâmica e políticas de incentivo à inovação em âmbito nacional. O referencial teórico adotado refere-se as aglomerações de empresas segundo a abordagem neoschumpeteriana. Para a realização desse estudo, a técnica de pesquisa empregada pautou-se em entrevistas orientadas por questionário, que foram realizadas nas empresas e em instituições de apoio pertencentes as duas aglomerações durante pesquisa de campo para tese de doutorado. Ao todo foram entrevistadas 18 empresas em Coimbra, e nove empresas em Curitiba. Defende-se que o ambiente institucional vai impactar decisivamente nos processos de cooperação, de transferência de conhecimento e aprendizado, tanto formal quanto informal. Ao final, foi possível confirmar a relevância do ambiente institucional, das políticas públicas e dos diversos atores nessa dinâmica.
\end{abstract}

Palavras-chave: Aglomerações de empresas. Tecnologia da Informação e Comunicação (TIC). Inovação. Interação.

ABSTRACT: This work aims to analyze how the interaction and cooperation, both formal and informal, between companies and institutions belonging to the technology centers of the Information and Communication Technology (ICT) sector, in Curitiba (Brazil) and Coimbra (Portugal) Act as a key factor for innovation to take place. From the analysis of the theory and the interviews conducted, we intend to compare the two clusters, as well as the different forms of interaction that occur in them, verifying how they potentiate the transfer of knowledge and learning among the agents. At the same time, it seeks to verify the innovative dynamics specific to each cluster in the local context, based also on the dynamics and policies to encourage innovation at the national level. The theoretical reference adopted referring to clusters of firms according to a neoschumpeterian approach. In order to carry out this study, the research technique employed was based on questionnaire-based interviews, which were carried out in companies and support institutions belonging to the two clusters during field research for doctoral thesis. In all, 18 companies were interviewed at the Coimbra center, and nine companies were in Curitiba. It is argued that the institutional environment will have a decisive impact on the processes of cooperation, knowledge transfer and learning, both formal and informal. In the end, it was possible to confirm the relevance of the institutional environment, public policies and the various actors in this dynamic.

Key-words: Clusters of firms. Information and Communication Technology (ICT). Innovation. Interaction.

1 Doutoranda no Programa de Pós-Graduação em Políticas Públicas da Universidade Federal do Paraná. E-mail: pollygondin@gmail.com

2 Professor no Programa de Pós-Graduação em Políticas Públicas da Universidade Federal do Paraná. E-mail: waltershima@ufpr.br

${ }^{3}$ Universidade de Coimbra. E-mail: nunoteles@ces.uc.pt 


\section{INTRODUÇÃO:}

A temática relacionada a polos tecnológicos do setor de TIC, aos efeitos interativos entre os agentes e à dinâmica de inovação proveniente dessa interação vem sendo debatida tanto na literatura acadêmica quanto no âmbito das políticas públicas, dada a crescente importância desse setor e dos efeitos interativos entre empresas e instituições para o crescimento e desenvolvimento econômico de países. Isso ocorre, uma vez que, a concentração geográfica de empresas de um mesmo setor aumenta a capacidade de avanço tecnológico, propiciando a intensificação das articulações e interações, que podem impactar positivamente na geração de aprendizado, conhecimento e, por consequência, no processo inovativo. Apesar disso, essa temática pode ser considerada recente, pois ganhou destaque após a Terceira Revolução Industrial.

Levando em consideração a relevância dessa temática, este trabalho tem como objetivo analisar como os processos de interação e cooperação, tanto formal quanto informal, atuam como fator-chave para que a inovação ocorra em empresas de micro e pequeno porte. Busca-se, por meio de comparação, verificar se ocorreu interação, cooperação e consequente aprendizado entre os diversos atores durante o período analisado, bem como suas formas, sejam elas formais ou informais, fatores condicionantes e seus impactos para as empresas.

A fim de se cumprir com o objetivo do trabalho, e em se tratando de uma pesquisa que requer um aprofundamento de categorias teóricas fundamentais, inicialmente, realizou-se uma busca bibliográfica da literatura, abarcando a temática relacionada aos sistemas de inovação. Discutiu-se a literatura referente a aglomerações de empresas para abarcar tanto o caso português quanto o caso brasileiro. Feita a revisão bibliográfica, voltou-se atenção para os estudos dos dois casos que serão comparados: a aglomeração de TIC de Coimbra, representado pelo Instituto Pedro Nunes (IPN), e a de TIC de Curitiba, também conhecida como APL de Software de Curitiba.

Vale ressaltar que a comparação dos dois casos é feita por meio da combinação de várias técnicas de pesquisa e fontes de dados. Primeiramente, foram coletados dados secundários acerca do contexto das duas aglomerações, nas esferas macro, regional e setorial. As coletas deram-se por uma busca detalhada em sites oficiais dos dois países. Além dos dados secundários, foram feitas, para os dois casos, entrevistas com questionário semiestruturado nas instituições de apoio e nas empresas. A realização dessas entrevistas foi importante, pois permitiu coletar informações que não são codificadas. A comparação dos dois casos visa a analisar a dinâmica inovativa das TICs e a avaliar em que medida a proximidade territorial e as interações entre os agentes favorecem o processo inovativo em aglomerações de TIC, verificando qual ambiente institucional é mais propício para gerar a interação.

Assim, por meio de estudos comparativos, é possível verificar as semelhanças e as diferenças em casos localizados em economias distintas, permitindo examinar quais os fatores, os atores-chaves e o ambiente institucional que compõem as aglomerações. Nesse aspecto, o estudo proposto visa identificar as similaridades e as diferenças entre as aglomerações de TIC de Curitiba e de Coimbra, verificando o ambiente institucional e sua influência na interação, cooperação e consequente inovação. É importante salientar que cada aglomeração possui especificidades e vínculos locais.

Levando em consideração a importância dessa temática e visando a cumprir o objetivo do estudo, este trabalho está estruturado em cinco seções, para além desta introdução. Na primeira seção faz-se uma revisão teórica acerca da inovação ressaltando a abordagem neoschumpeteriana das aglomerações de empresas e as características das TICs e produção de software. A segunda seção dedica-se a apresentação da metodologia utilizada para a realização do estudo comparativo. Na terceira seção realiza-se a análise e comparação das duas aglomerações. A quarta seção refere-se às considerações finais do trabalho, e por fim, na quinta seção são apresentadas as referências bibliográficas.

\section{REFERENCIAL TEÓRICO:}

Levando em consideração a relevância, a incerteza e a complexidade que envolvem o processo inovativo, esta seção desdobra-se no estudo do significado da inovação tecnológica, que ganhou destaque no debate acadêmico pelos escritos schumpeterianos e suas posteriores interpretações por autores 
neoschumpeterianos, também conhecidos como evolucionistas. Para cumprir com esse objetivo e visando a abarcar o processo de inovação na economia capitalista, faz-se, uma caracterização do modelo sistêmico de inovação, abarcando as aglomerações de empresas.

O objeto de estudo deste trabalho diz respeito à interação entre os diversos agentes na geração de inovação no setor de TIC, que supostamente é inovador por definição. A trajetória tecnológica e a capacidade de inovação de uma indústria estão fortemente relacionadas com o arcabouço institucional que conforma o ambiente de seleção. Todas essas questões tornam relevantes a noção de sistemas e a análise das aglomerações de empresas. Quando a ideia de desenvolvimento tecnológico e inovação vem à tona, devemos ter em mente a noção de sistemas. Diferentemente do que considera o modelo linear, para ocorrer o desenvolvimento tecnológico e a inovação propriamente dita, é necessária a convergência de interesses conflitantes entre os diversos atores envolvidos. Hughes (1983) afirma que, em um sistema sociotécnico, as relações entre os envolvidos são conflituosas e requerem negociações. Deste modo, a tecnologia desenvolvida, os empresários, o governo, a sociedade, as legislações sobre patentes, os clientes, dentre outros, interligam-se e configuram um sistema.

A aglomeração de empresas possibilita que micro e pequenas empresas obtenham vantagens competitivas, uma vez que nesta concentração tende a ocorrer uma maior cooperação, uma maior difusão de conhecimento e de tecnologia, dentre outros fatores, que sustentam o crescimento dessas empresas frente ao mercado. Foi então que a fim de se entender o desempenho competitivo das empresas, várias teorias passaram a analisar as relações entre as empresas e entre essas e outras instituições que estão inseridas em um mesmo espaço geográfico. Esse enfoque, de acordo com Cassiolato e Lastres (2004), orienta as políticas governamentais destinadas à indústria e à tecnologia na atualidade.

A análise da REDESIST leva em consideração a visão neoschumpeteriana sobre sistemas de inovação, sendo que essa visão enfatiza o caráter localizado e específico dos processos de aprendizagem e inovação, preocupando-se mais com a questão espacial. De acordo com Cassiolato e Lastres (2004), o conhecimento tácito passa a adquirir grande importância, assim como as instituições e organizações, suas políticas e todo o ambiente sociocultural onde se inserem os agentes econômicos. A consideração desses aspectos determina que a questão da localização geográfica assuma grande relevância para os neoschumpeterianos, na medida em que aspectos intrínsecos à localização influenciarão no processo de geração de inovação.

Segundo os autores em questão, a proposta de se entender Sistemas e Arranjos Produtivos Locais, fundamenta-se na visão evolucionista sobre inovação e mudança tecnológica:

\footnotetext{
- O reconhecimento de que inovação e conhecimento colocam-se cada vez mais visivelmente como elementos centrais da dinâmica e do crescimento de nações, regiões, setores, organizações e instituições;

- A compreensão de que a inovação e o aprendizado, enquanto processos dependentes de interações, são fortemente influenciados por contextos econômicos, sociais, institucionais e políticos específicos;

- A ideia de que existem marcantes diferenças entre os agentes e suas capacidades de aprender, as quais refletem e dependem de aprendizados anteriores;

- A visão de que se, por um lado, informações e conhecimentos codificados apresentam condições crescentes de transferência (...) conhecimentos tácitos de caráter localizado e específico continuam tendo um papel primordial para o sucesso inovativo e permanecem difíceis (senão impossíveis) de serem transferidos (CASSIOLATO; LASTRES, 2004, p. 24).
}

Assim, é a partir dos preceitos da visão evolucionista sobre inovação e mudança tecnológica, que a REDESIST se propõe a caracterizar APLs, levando em consideração o conceito de Sistema de Inovação (SI) que se refere a um conjunto de instituições distintas que coletivamente e individualmente contribuem para a difusão e desenvolvimento de tecnologias. Cassiolato e Lastres (2004, p. 25) afirmam que (...) tal sistema é constituído por elementos onde diferenças básicas em experiências históricas, culturais e de língua refletem-se em idiossincrasias em termos de: organização interna das empresas, articulação entre elas e outras organizações, características sociais, econômicas e políticas do ambiente local, papel das agências e políticas públicas e privadas, do setor financeiro, etc. 
É possível perceber então que, quando instituições, tanto conjunta quanto individualmente, colaboram no desenvolvimento de tecnologias, tem-se um sistema de inovação, sendo este sistema baseado em conceitos de aprendizagem, interações entre os indivíduos e agentes econômicos, complementaridades, governança, dentre outros. Estudar aglomerações de empresas levando em consideração os sistemas de inovação visa entender como estas se organizam para criar competitividade através da inovação tecnológica.

A partir do conceito de SI, a REDESIST desenvolveu os conceitos de Arranjo Produtivo Local (APL) e de Sistema Produtivo e Inovativo Local (SPIL). Esses conceitos foram desenvolvidos para auxiliar na análise das interações entre os agentes econômicos, tanto entre as empresas quanto com instituições públicas e privadas, principalmente aquelas que levam à introdução de novas técnicas e novos produtos. As relações entre esses agentes, os fluxos de conhecimento, as políticas voltadas para esse arranjo, o processo de aprendizado, a importância da proximidade geográfica, a identidade cultural e social que são capazes de gerar eficiência e vantagens competitivas para seus agentes são elementos de grande relevância para o estudo dos APLs e dos SPILs.

A REDESIST considera então que APLs são:

Aglomerações territoriais de agentes econômicos, políticos e sociais - com foco em um conjunto específico de atividades econômicas - que apresentam vínculos mesmo que incipientes. Geralmente envolvem a participação e a interação de empresas - que podem ser desde produtoras de bens e serviços finais até fornecedoras de insumos e equipamentos, prestadoras de consultoria e serviços, comercializadoras, clientes, entre outros - e suas várias formas de representação e associação. Incluem também diversas outras instituições públicas e privadas voltadas para: formação e capacitação de recursos humanos (como escolas técnicas e universidades); pesquisa, desenvolvimento e engenharia; política, promoção e financiamento (CASSIOLATO; LASTRES, 2004, p.27).

Já os SPILs são aqueles arranjos produtivos em que

(...) interdependência, articulação e vínculos consistentes resultam em interação, cooperação e aprendizagem, com potencial de gerar o incremento da capacidade inovativa endógena, da competitividade e do desenvolvimento local (CASSIOLATO; LASTRES, 2004, p. 27).

Segundo a REDESIST, pode-se considerar que Arranjos e Sistemas Produtivos e Inovativos Locais abrangem um

\begin{abstract}
(...) conjunto de atores econômicos, políticos e sociais e suas interações, incluindo: empresas produtoras de bens e serviços finais e fornecedores de matérias-primas, equipamentos e outros insumos; distribuidoras e comercializadoras; trabalhadores e consumidores; organizações voltadas à formação e treinamento de recursos humanos, informação, pesquisa, desenvolvimento e engenharia; apoio, regulação e financiamento; cooperativas, associações, sindicatos e demais órgãos de representação (CASSIOLATO; LASTRES; STALLIVIERI, 2009, p.14).
\end{abstract}

Ao abordar a temática sobre aglomerações, torna-se importante também, analisar a questão da aprendizagem por interação entre as empresas que se mostra fundamental para a criação de vantagens competitivas das firmas, ao possibilitar o avanço tecnológico de informação e comunicação dos aglomerados. No que diz respeito à aprendizagem, Dogson (1996, apud CAMPOS et al, 2004, p. 52) considera que a mesma,

(...) pode ser descrita como as formas pelas quais as firmas constroem e organizam conhecimentos e rotinas em torno de suas competências e dentro de sua cultura, e adaptam e desenvolvem eficiência organizacional melhorando o uso de suas competências.

Se faz necessário ressaltar que, apesar do conhecimento e o aprendizado serem desenvolvidos dentro das empresas que constituem o aglomerado, as fontes dos mesmos estão localizadas tanto dentro dessas quanto externamente, sendo que a relação de uma firma com outras firmas e organizações gera a 
aprendizagem por interação (learning by interacting). Assim sendo, Lundvall e Johnson (2001:12, apud CAMPOS et al, 2004, p.53) consideram

(...) o conhecimento como um recurso que não é nem completamente público, nem completamente privado, e cuja base é fragmentada. A propriedade pública ou privada do conhecimento cria mediações específicas para sua transferência, afetando as condições de acessibilidade e de uso do conhecimento.

Tratando-se do conhecimento no processo de aprendizagem, esse pode ter natureza tácita ou codificada (CAMPOS et al, 2004). O conhecimento tácito é difícil de ser expresso, sendo a melhor forma de transmiti-lo por meio da convivência e observação, o que implica fundamentalmente a necessidade de interação, ressaltando a importância dos códigos de compartilhamento entre as empresas e fazendo com que o contexto social seja relevante para a transferência desse conhecimento.

Para haver aprendizado dentro de um APL, a confiança entre os agentes se torna uma questão fundamental. A esse respeito, Campos et al (2004) defendem que o processo de aprendizagem no interior de um sistema local de inovação está relacionado com a interação que é facilitada pelos códigos comuns de comunicação e pelo compartilhamento de convenções entre os agentes, reforçando a confiança entre os mesmos. Deste modo, para a REDESIST,

(...) onde houver produção de qualquer bem ou serviço haverá sempre um arranjo em seu torno, envolvendo atividades e atores relacionados à sua comercialização, assim como aquisição de matérias-primas, máquinas e demais insumos. As exceções são muito raras. Tais arranjos variarão desde aqueles mais rudimentares àqueles mais complexos e articulados (CASSIOLATO; LASTRES, 2004, p. 31).

\subsection{CARACTERÍSTICAS INTRÍNSECAS AS TECNOLOGIAS DA INFORMAÇÃO E COMUNICAÇÃO E À PRODUÇÃO DE SOFTWARE}

O software é a parte imaterial dentro de um sistema computacional e se refere a todo um conjunto de elementos técnicos específicos da inteligência humana que controlam e operam computadores ou sistema de computadores. Com base em Messerschmitt e Szyperski (2003) pode-se afirmar que o software é um elemento que está cada vez mais presente em todo equipamento informatizado implicando cada vez mais a produção e processamento de informações. Dessa forma, os equipamentos sendo mais "inteligentes" há um processo crescente e sofisticado de interação homem-máquina. Nesse sentido, o software torna-se pervasivo reforçando a chamada Economia do Conhecimento, dado o seu caráter transversal e abrangente que demanda, portanto, ampla atenção das políticas de Ciência e Tecnologia (C\&T).

A natureza "inteligente" do software significa que guarda amplas características humanas, uma vez que, requer habilidades na sua concepção e design. Ou seja, o software em certa medida guarda os interesses e visões do seu produtor, que é humano. Desse modo, o software tem o grande poder de conduzir a formação e operação das ações da sociedade em geral. Mas ao mesmo tempo seu desenvolvimento é social na medida em que sua criação implica interatividade, interdisciplinaridade e ação coletiva, uma vez que, sua produção busca atender interesses de uma coletividade complexa de vários tipos de usuários (com diversos interesses e expectativas). Daí que cooperação é de suma importância e seu desenvolvimento é interminável. Considera-se também que a melhoria é contínua via processos interativos. Assim, cada vez mais a interação se torna fundamental em função do aumento da complexidade dos sistemas computacionais que exigem diversos conhecimentos decorrentes da necessidade de integrar diversos sistemas com padrões proprietários. Desse modo, de uma comunidade aberta com a perspectiva de troca de conhecimento, o software evolui para uma indústria competitiva com elevado grau de concentração em segmentos que conseguiram se estabelecer como padrão dominante. (SAMPAIO, 2006).

Mas ao mesmo tempo em que cada vez mais aumenta a dominância de padrões proprietários seu uso e desenvolvimento de versões futuras requer interações produtor-usuário-novos produtores. Padrões dominantes não impedem o surgimento de novos e melhores aplicativos complementares que rodam em sistemas proprietários dominantes. Desse modo, dado a o processo competitivo e aceitação no mercado 
esse crescente surgimento de novos aplicativos continua demandando processos interativos no desenvolvimento e integração de sistemas.

\section{METODOLOGIA}

Para a realização deste estudo, a pesquisa de campo dividiu-se em duas partes. Em 2015, dedicouse à realização de entrevistas e aplicação de questionários ${ }^{4}$ no polo de Coimbra. Já no primeiro semestre de 2016, realizou-se a coleta de dados e entrevistas em Curitiba. A técnica de pesquisa empregada foi a realização de entrevistas com questionário semiestruturado com a população dos dois polos. A amostra foi definida segundo a acessibilidade e foi delimitada através da saturação das informações. Em Coimbra definiu-se uma amostra de 18 empresas e em Curitiba, de nove empresas. Nos dois polos, as entrevistas foram realizadas com as empresas e instituições de apoio. A comparação dos dois casos visa a analisar a dinâmica inovativa das TICs e a avaliar em que medida a proximidade territorial e as interações entre os agentes, favorecem o processo inovativo nas duas aglomerações de TIC, verificando qual ambiente institucional é mais propício para gerar a inovação.

Inicialmente, o foco do trabalho era entrevistar empresas de TIC que possuíssem Classificação Portuguesa das Atividades Econômicas (CAE) - Rev.3, 62 (Consultoria e Programação Informática e Atividades Relacionadas) e 63 (Atividades dos Serviços de Informação). Porém, no decorrer das entrevistas, optou-se por alargar essa amostra, dado que, segundo as próprias empresas, o CAE muitas vezes não reflete a real atividade desenvolvida. E assim foi possível perceber com o estudo de campo que empresas com diferentes CAEs também possuem como segmento principal atividades relacionadas às TICs. Para a aglomeração brasileira, utilizou-se a Classificação Nacional de Atividades Econômicas (CNAE) 2.0 Revisão 2, que é a classificação oficial adotada pelo Sistema Estatístico Nacional e pelos demais órgãos tanto em nível federal, quanto estadual e municipal. É importante ressaltar que essa classificação possui correspondência com a classificação utilizada em Portugal.

\section{ANÁlISE E COMPARAÇÃO DOS POLOS DE TIC DE COIMBRA E DE CURITIBA}

O Instituto Pedro Nunes (IPN) é uma associação para a inovação e desenvolvimento em Ciência e Tecnologia, classificado como uma instituição de direito privado, de utilidade pública e sem fins lucrativos. Esse instituto localiza-se em Coimbra, cidade situada na região Centro de Portugal. O IPN foi criado em 1991, pela Universidade de Coimbra, para fazer interface entre o conhecimento gerado na universidade e o tecido empresarial. Tanto o Estado português quanto a União Europeia atuaram financiando a construção de edifícios e a contratação de pessoal para o instituto.

O APL de Software de Curitiba, por sua vez, é uma instituição criada para apoiar as empresas de software de Curitiba e região. Essa instituição não possui fins lucrativos e nem uma personificação jurídica. Tem como objetivo liderar o sistema de TIC com empresas e inovadoras, por meio do reconhecimento local, regional e nacional. É composta pela capital paranaense e alguns municípios da sua região metropolitana, tais como Pinhais, São José, Colombo e Araucária. Começou a ser criada no ano de 2006, para atender os interesses de diversos atores e instituições, principalmente no que se refere à alavancagem de recursos. Assim, em 2012, diante da demanda por parte das empresas, por uma instituição para efetuar compras coletivas criou-se a CENETIC, que atua conjuntamente a instituição APL.

\subsection{PERFIL DAS EMPRESAS ENTREVISTADAS}

Antes de realizar a análise dos dados respectivos ao aprendizado, à cooperação e à inovação, é relevante apresentar o perfil das empresas que foram entrevistadas nos dois polos.

No IPN, das 18 empresas entrevistadas, todas possuem localização em Coimbra, sendo que, destas, duas possuem também localização em outras regiões. Uma delas localiza-se em Coimbra e Lisboa, e a outra possui sede em Lisboa e outros escritórios em Coimbra, Oeiras, Porto, Bruxelas, São Paulo, Luanda e

\footnotetext{
${ }^{4}$ Salienta-se que o questionário base utilizado foi desenvolvido pela Rede de Pesquisa em Sistemas e Arranjos Produtivos e Inovativos Locais (REDESIST) em 2003. Apesar disso, foram feitas algumas alterações para adaptar à pesquisa.
} 
Irlanda. Além disso, dentre as 18 empresas da amostra, oito encontram-se em processo de incubação virtual, nove em incubação física e uma está instalada na aceleradora de empresas da instituição. Das empresas incubadas virtualmente, salienta-se que sete não possuem uma instalação física e utilizam a sala de coworking localizada na própria instituição.

No APL de Software de Curitiba, das nove empresas entrevistadas, todas se localizam em Curitiba, sendo que uma delas também possui filial em Araruna, cidade do interior do Paraná. Ademais, duas das empresas entrevistadas possuem localização no Parque de Software da cidade, três localizam-se na região central, uma no bairro Bigorrilho, uma no bairro Jardim Social, uma no Seminário e outra no bairro Novo Mundo. As duas empresas que se localizam no Parque de Software utilizam de salas dessa instituição.

A Tabela 1 apresenta os resultados referentes à composição da amostra dos dois polos. A partir da análise da tabela, pode-se verificar que no IPN as empresas de consultoria e programação informática e atividades relacionadas são maioria na amostra selecionada. Dentro desse segmento, existem empresas que atuam na criação de mídias, programas e aplicativos na área de educação, empresas que possuem como atividade principal o desenvolvimento de projetos e consultoria em softwares e empresas que trabalham com conteúdo e serviços voltados para a saúde.

No APL de Software de Curitiba, por sua vez, o segmento de atividade principal das empresas concentra-se no código CNAE 62. Todas as empresas da amostra trabalham com o desenvolvimento de softwares. Apesar dessa concentração, deve-se salientar que os softwares desenvolvidos atendem a diversas áreas. Como exemplo, uma das empresas trabalha com desenvolvimento de software para atender corretoras de seguros, outra empresa trabalha com o desenvolvimento de sistema para gestão de laboratórios para análises e ensaios e também com software para gestão de calibração e metrologia, possuindo como clientes, por exemplo, a FIAT e a Petrobrás. Ademais, existem empresas que desenvolvem sistemas para o setor educacional, para o comércio e indústria, para atender o setor alimentício, para as áreas financeira, gestão de qualidade e logística, dentre outros.

Se comparadas com as empresas de Curitiba, as empresas do polo de Coimbra apresentam uma maior diversificação dos segmentos de atividades. Levando em consideração a pesquisa de campo e o contato com os empresários, esse fato pode estar relacionado a duas questões. Primeiro, os empresários de Coimbra apresentaram maior espírito empreendedor. Esse fato pode estar relacionado com a necessidade de inovar para fazer frente à grande competitividade que as empresas portuguesas enfrentam, visto a proximidade com várias economias europeias, além da jovialidade de parte dos empresários que, por serem mais novos, acabam por arriscar mais em invenções. Segundo, para atender o mercado, as empresas de Curitiba enxergaram nas atividades de consultoria e programação grande possibilidade de sucesso já que, com o desenvolvimento de sistemas, pode-se atender à demanda de um grande número de empresas de diversos ramos e setores.

TABELA 1 - DISTRIBUIÇÃO DAS EMPRESAS DA AMOSTRA POR SEGMENTO DE ATIVIDADE PRINCIPAL

\begin{tabular}{l|c|c|c|c}
\hline \multirow{2}{*}{ Principais Segmentos Segundo CAE5 / CNAE } & \multicolumn{2}{|c|}{ IPN $^{\mathbf{5}}$} & \multicolumn{2}{c}{$\begin{array}{c}\text { APL de Software de } \\
\text { Curitiba }\end{array}$} \\
\cline { 2 - 5 } & $\begin{array}{c}\mathbf{N}^{\mathbf{0}} \\
\text { Empresas }\end{array}$ & $\%$ & $\begin{array}{c}\mathbf{N}^{\mathbf{0}} \\
\text { Empresas }\end{array}$ & $\%$ \\
\hline $\begin{array}{l}\text { 26 - Fabricação de equipamentos informáticos, para comunicações } \\
\text { e produtos eletrônicos e óticos }\end{array}$ & 1 & 5,90 & 0 & 0,00 \\
\hline $\begin{array}{l}62-\text { Consultoria e programação informática e atividades } \\
\text { relacionadas (Port.) / Ativ. dos Serviços de TI }\end{array}$ & 8 & 47,00 & 9 & 100,00 \\
\hline 63 - Atividades dos Serviços de Informação & 3 & 17,60 & 0 & 0,00 \\
\hline 70 - Atividades das sedes sociais e de consultoria para gestão & 1 & 5,90 & 0 & 0,00 \\
\hline
\end{tabular}

\footnotetext{
${ }^{5}$ CAE - Rev.3.

${ }^{6}$ CNAE - Rev. 2.0.

${ }^{7}$ Os dados do IPN foram construídos tendo como base 17 empresas, já que uma das empresas está em fase de constituição formal e ainda não possui CAE. Porém, levando em consideração a atividade desenvolvida por ela, pode-se ressaltar que o CAE possuirá divisão 62.
} 


\begin{tabular}{l|c|c|c|c}
\hline $\begin{array}{l}71-\text { Atividades de arquitetura, de engenharia e técnicas afins; } \\
\text { atividades de ensaios e de análises técnicas }\end{array}$ & 2 & 11,80 & 0 & 0,00 \\
\hline $\begin{array}{l}74 \text { Outras atividades de consultoria, científicas, técnicas e } \\
\text { similares }\end{array}$ & 2 & 11,80 & 0 & 0,00 \\
\hline TOTAL & $\mathbf{1 7}$ & $\mathbf{1 0 0 , 0 0}$ & $\mathbf{9}$ & $\mathbf{1 0 0 , 0 0}$ \\
\hline
\end{tabular}

Fonte: Elaboração própria com base em pesquisa de campo (2015-2016).

Os resultados da pesquisa de campo refletem uma característica importante não apenas da amostra, mas da população dos dois polos. No que se refere ao tamanho, segundo o número de funcionários, as empresas, no IPN, são em sua maioria de pequeno porte, possuindo até dez funcionários, representando cerca de $77 \%$ das empresas entrevistadas. Entretanto, apesar de serem maioria, essas empresas são responsáveis por $12,1 \%$ dos postos de trabalho gerados. No IPN, a amostra entrevistada foi composta também por uma grande empresa que possui um total de 500 funcionários, responsável pela geração de $79,3 \%$ do emprego.

No APL de Software de Curitiba, todas as empresas entrevistadas possuem até 50 funcionários, sendo a amostra bem distribuída no que se refere ao tamanho segundo número de funcionários. Três empresas desse polo possuem até dez funcionários, outras três possuem de 11 a 20 funcionários, duas empresas possuem de 21 a 30 funcionários e uma empresa possui de 31 a 50 funcionários. Os dados apresentados pela amostra de empresas vão ao encontro da realidade nacional, de acordo com dados do SEBRAE (2013). Segundo essa instituição, 99\% das empresas brasileiras são de micro e pequeno porte ${ }^{8}$ e respondem por $52 \%$ dos empregos com carteira assinada no setor privado.

A respeito do perfil das empresas entrevistadas nos dois polos, o Quadro 1 foi elaborado com o intuito de reunir as principais características e diferenças entre os dois polos. Em síntese, as empresas pertencentes as duas aglomerações apresentam características semelhantes, embora algumas diferenças são consideradas. Por exemplo, a constituição recente das empresas do IPN em comparação à constituição das empresas do polo de Curitiba. Além disso, como considerado, apesar da maioria das empresas do IPN apresentar CAE 62, existe uma maior diversificação em termos dos segmentos de atividades.

QUADRO 1 - SÍNTESE DO PERFIL DAS EMPRESAS ENTREVISTADAS

\begin{tabular}{|l|l|l|}
\hline \multicolumn{1}{|c|}{$\begin{array}{l}\text { Localização das } \\
\text { empresas da amostra }\end{array}$} & $\begin{array}{l}\text { Todas em Coimbra, sendo que uma também } \\
\text { possui escritório em Lisboa e outra possui em } \\
\text { Lisboa. Bruxelas, Porto, SP, Luanda e Irlanda. }\end{array}$ & $\begin{array}{l}\text { APL de Software de Curitiba/CENETIC } \\
\text { Todas em Curitiba, sendo que uma também } \\
\text { possui escritório em Araruna. }\end{array}$ \\
\hline Instalações & $\begin{array}{l}7 \text { empresas não possuem sede física e usam } \\
\text { sala de co-working. }\end{array}$ & $\begin{array}{l}\text { 2 empresas localizam-se no Parque de } \\
\text { Software e utilizam sala dessa instituição. }\end{array}$ \\
\hline Setor & CAE 62 predominante & CNAE 62 totalidade da amostra \\
\hline Porte das empresas & $\begin{array}{l}\text { Maioria das empresas com até 10 } \\
\text { funcionários. Possui uma grande empresa com } \\
500 \text { funcionários. }\end{array}$ & $\begin{array}{l}\text { Maioria das empresas com até 20 } \\
\text { funcionários. Não possui nenhuma empresa de } \\
\text { grande porte. }\end{array}$ \\
\hline $\begin{array}{l}\text { Constituição das } \\
\text { empresas }\end{array}$ & $\begin{array}{l}72,2 \% \text { das empresas com constituição após } \\
2011, \text { caracterizadas como startups. }\end{array}$ & $\begin{array}{l}77,8 \% \text { das empresas com constituição na } \\
\text { década de 1990 a 2005. }\end{array}$ \\
\hline Capital controlador & $\begin{array}{l}88,9 \% \text { das empresas possuem capital } \\
\text { controlador nacional. }\end{array}$ & $\begin{array}{l}100 \% \text { das empresas possuem capital } \\
\text { controlador nacional. }\end{array}$ \\
\hline $\begin{array}{l}\text { Sócio-fundador - } \\
\text { Sexo, idade, ensino }\end{array}$ & $\begin{array}{l}94,4 \% \text { das empresas possuem sócio-fundador } \\
\text { homem. Todas com sócio-fundadores com } \\
\text { menos de 40 anos. Todos com ensino superior } \\
\text { completo, sendo 44,4\% com pós-graduação. }\end{array}$ & $\begin{array}{l}\text { 100\% das empresas possuem sócio-fundador } \\
\text { homem. 88,9\% dos sócios com menos de 40 } \\
\text { anos. 88,9\% dos sócios com superior } \\
\text { completo, sendo 33,3\% com pós-graduação. }\end{array}$ \\
\hline
\end{tabular}

Fonte: Elaboração própria com base em pesquisa de campo (2015-2016).

\footnotetext{
${ }^{8}$ Segundo classificação do SEBRAE, as empresas brasileiras podem ser classificadas de acordo com a Receita Bruta Anual e quanto ao número de empregados. São consideradas microempresas, estabelecimentos com até 19 funcionários na indústria e até nove no setor comercial e de serviços. Pequenas empresas são aquelas que possuem de 20 a 99 empregados no setor industrial e de 10 a 49 no comércio e serviços. As médias empresas possuem de 100 a 499 funcionários no setor industrial e de 50 a 99 no setor comercial e de serviços. Por fim, empresas com mais de 500 funcionários no setor industrial e com mais de 100 no setor comercial e de serviços são classificadas como empresas de grande porte. Disponível em: <http://www.sebraesc.com.br/leis/default.asp?vcdtexto=4154>.
} 
A partir deste momento, volta-se atenção para a estrutura, governança e vantagens associadas ao ambiente local.

\subsection{ESTRUTURA E VANTAGENS ASSOCIADAS AO AMBIENTE LOCAL}

Parte do questionário aplicado nas empresas entrevistadas nos polos de Coimbra e de Curitiba dedicou-se à investigação da ocorrência de externalidades. Segundo Santos, Crocco e Lemos (2002), a aglomeração de empresas em determinada localidade facilita e estimula as interações coletivas, permitindo que os agentes desenvolvam ligações entre um sistema de produção e uma cultura tecnológica específica, devido justamente a essa proximidade física. Tal fato possibilita a difusão de um aprendizado coletivo e de conhecimento tácito.

Levando em consideração o conceito de externalidades difundido pela teoria econômica, analisaram-se as respostas fornecidas pelas empresas de TICs que participam das ações das duas aglomerações. A Tabela 2 apresenta as principais vantagens da localização para as empresas desses polos, com seus respectivos índices de relevância ${ }^{9}$. Essa questão tentou captar a importância da localidade, isto é, as externalidades possibilitadas pela localização do polo e das empresas.

De acordo com os resultados obtidos na pesquisa (Tabela 2), percebe-se que as duas aglomerações estudadas, podem ser consideradas, no que diz respeito às externalidades, como incompletas. Isso ocorre, pois, atividades relevantes da cadeia produtiva, como fornecedores de equipamentos, disponibilidade de serviços técnicos especializados, proximidade com produtores de equipamentos, são algumas das atividades que não se encontram localmente, ou seja, possuem pequena importância local para as empresas entrevistadas desse aglomerado.

TABELA 2 - VANTAGENS ASSOCIADAS À LOCALIZAÇÃO DAS EMPRESAS

\begin{tabular}{l|c|c}
\hline \multirow{2}{*}{ Externalidades nos polos } & \multirow{2}{*}{ IPN } & $\begin{array}{c}\text { APL de Software de } \\
\text { Curitiba }\end{array}$ \\
\hline Disponibilidade de mão de obra qualificada & Índice de Relevância & Índice de Relevância \\
\hline Baixo custo da mão de obra & 0,50 & 0,57 \\
\hline Proximidade com os fornecedores de insumos e matéria-prima & 0,05 & 0,03 \\
\hline Proximidade com os clientes/consumidores & 0,06 & 0,10 \\
\hline Infraestrutura física (energia, transporte, comunicações) & 0,07 & 0,41 \\
\hline Proximidade com produtores de equipamentos & 0,46 & 0,47 \\
\hline Disponibilidade de serviços técnicos especializados & 0,00 & 0,00 \\
\hline Existência de programas de apoio e promoção & 0,28 & 0,20 \\
\hline Proximidade com universidades e centros de pesquisa & 0,42 & 0,66 \\
\hline
\end{tabular}

Fonte: Elaboração própria com base em pesquisa de campo (2015-2016).

Os dados referentes ao grau de importância das transações comerciais realizadas localmente para as empresas de TICs do IPN e do APL de Software de Curitiba reforçam os argumentos da Tabela 2, que dizem respeito às vantagens da localização. Em Coimbra, todas as transações apresentaram baixa importância, sendo a venda de produtos e/ou serviços a que mais se destacou, embora com índice de relevância de 0,37 . No polo de Curitiba, apenas a venda de produtos e a aquisição de insumos apresentaram índice de relevância maior que 0,50 , sendo 0,56 e 0,58 , respectivamente.

No IPN, a transação que apresentou maior índice de relevância foi a venda de produtos e/ou serviços, embora seja um nível de relevância baixo. Um dos entrevistados afirmou que 95\% das vendas realizadas pela empresa são para outros mercados que não o português. Outros dez entrevistados exportam entre $70 \%$ e $90 \%$ dos seus produtos e serviços, atendendo mercados como Estados Unidos, Reino Unido,

\footnotetext{
9 Índice de Relevância $=\left(0^{*} \mathrm{~N}^{\circ}\right.$ Nulas $+0,3^{*} \mathrm{~N}^{\circ}$ Baixas $+0,6^{*} \mathrm{~N}^{\circ}$ Médias $+\mathrm{N}^{\circ}$ Altas $) /\left(\mathrm{N}^{\circ}\right.$ Empresas no Segmento $)$. Este índice varia entre 0 e 1 , sendo que quanto mais próximo de 1 estiver, mais importante é o item em questão.
} 
Espanha, Brasil, Holanda, Irlanda, dentre outros. Além disso, a aquisição de equipamentos, componentes e serviços são, em sua maioria, importados de outros países.

Já no APL de Software de Curitiba, a aquisição de insumos de produção e a venda de produtos e/ou serviços foram os quesitos que apresentaram maior índice de relevância. Quatro das empresas entrevistadas afirmaram que o maior mercado da empresa se localiza em Curitiba e região. A esse respeito, uma delas afirmou que " $90 \%$ dos clientes está em Curitiba, pois não tem braço para atuar fora. Tem poucos clientes fora, em Florianópolis, São Paulo e Santos". Um dos entrevistados afirmou que "60\% das vendas são feitas em Curitiba, o restante é para outros locais do país".

Entretanto, apesar da importância local, uma das empresas afirmou que "vende o serviço para todo o país, uma vez que implanta tudo remotamente, o que permite o acesso a mercados mais distantes sem aumento dos gastos". Outra empresa relatou que " $15 \%$ a $20 \%$ dos serviços são feitos para Curitiba, mas criaram um canal de vendas para atender e aumentar o mercado regional". De modo geral, as empresas possuem como foco de mercado Curitiba e região ou o Brasil, sendo que apenas duas afirmaram vender também para países da América Latina, como Colômbia e Bolívia.

Em relação às vantagens associadas ao ambiente local, as empresas do IPN também foram questionadas sobre as vantagens de estar localizadas em Portugal. Já no APL de Software de Curitiba, as empresas foram questionadas sobre as vantagens de se localizar no estado do Paraná, devido à grande magnitude territorial do Brasil. A esse respeito, no IPN, nove empresas afirmaram ser importante a localização no país português. As empresas desse polo afirmaram que a qualidade da mão de obra e o baixo custo de vida são fundamentais. Além disso, a economia portuguesa localiza-se em um local estratégico, tendo proximidade com outros países da Europa e até mesmo do continente africano. Duas empresas também afirmaram que a localização em Portugal é fundamental, pois o mercado de atuação é totalmente nacional.

Quando questionadas sobre as vantagens de se localizar em Portugal, outras nove empresas disseram não haver grandes benefícios a não ser a questão familiar. Muitas dessas possuem um mercado nacional pouco significativo, sendo que em sua maioria atendem o mercado global, sendo essa uma das questões que diferem os dois polos: o mercado de atuação. Apesar de metade das empresas afirmar não haver grandes benefícios em se localizar em Portugal, reconhecem que a presença da Universidade de Coimbra, mão de obra qualificada, baixo custo de vida e posição privilegiada do país são questões relevantes.

Nota-se que os resultados aqui apresentados em relação às externalidades e vantagens associadas ao ambiente local do polo do IPN podem estar relacionados com a recente constituição de grande parte das empresas e também pela própria característica das TICs. De acordo com La Rovere (2006), um dos benefícios do setor das TICs é a facilidade de relações com vários países, já que, apesar de apresentar vínculo ao local, são facilmente transferíveis entre países e adaptáveis às diversas economias. Esse fato pode tornar as empresas de TICs menos enraizadas ao local. Entretanto, as questões institucionais devem sempre ser levadas em consideração, como a atuação do IPN e a importância da UC para a constituição das empresas.

No que tange às empresas entrevistadas do APL de Software de Curitiba, quatro empresas afirmaram que poderiam estar localizadas em outros estados brasileiros. A esse respeito, um dos entrevistados afirmou que "se estivesse em outro lugar do Brasil, estaria um passo à frente, estaria melhor se estivesse em Florianópolis ou Recife, por exemplo, pois em Curitiba existe alguma coisa para quem vai atrás, pois existe pouca divulgação". Outro entrevistado disse que todos os clientes são nacionais e, assim, poderiam estar em qualquer outro lugar do país, inclusive com mais benefícios, sendo a questão familiar importante para a localização atual. Outro afirmou que a maior vantagem de estar no Paraná, mais especificamente em Curitiba, é a "proximidade com seus clientes, porém, se tivesse desenvolvimento WEB essa vantagem desapareceria".

Esta seção teve como finalidade investigar a ocorrência de externalidades e vantagens associadas ao ambiente local. As externalidades são fatores de grande importância para aglomerações de empresas, uma vez que, permite a superação de debilidades e facilita a interação entre os diversos atores. Essas questões facilitam a transmissão de conhecimento tácito, conhecimento este de difícil tradução. A esse respeito, o Quadro 2 apresenta a síntese das vantagens e debilidades associadas à localização. Por meio do 
quadro é possível extrair que tanto para o polo de Curitiba quanto para o polo do IPN a disponibilidade de mão de obra qualificada é uma relevante externalidade. Isso é confirmado pela presença da UC e ISEC em Coimbra e de grandes universidades como a UFPR, UTFPR, PUC-PR em Curitiba. Por outro lado, os custos da mão de obra são considerados altos, o que pode estar relacionado à alta qualificação do pessoal relacionado à área de TIC, como consultores e programadores.

Uma das diferenças entre os dois polos relaciona-se aos clientes. A esse respeito, nota-se que no IPN grande parte das empresas possui como mercado não apenas o nacional, mas também o internacional. Por outro lado, as empresas do polo de Curitiba, em sua maioria, possuem clientes localizados no estado do Paraná, algumas no Brasil, e apenas 22,2\% exportam seus serviços para países da América Latina. Essa diferença pode estar relacionada às dimensões territoriais dos dois países. Notou-se, durante pesquisa de campo, que as empresas portuguesas sentem a necessidade de produzir e pensar no mercado externo para prosperar, visto que o mercado interno é limitado. Já as empresas do polo de Curitiba acabam por se especializar em produzir sistemas e prestar serviços para determinado ramo de atividade e restrito a determinada localidade, visto os custos imputados para deslocamento.

QUADRO 2 - SÍNTESE DAS VANTAGENS ASSOCIADAS AO AMBIENTE LOCAL

\begin{tabular}{|l|l|l|}
\hline $\begin{array}{l}\text { Vantagens da } \\
\text { Localização }\end{array}$ & $\begin{array}{l}\text { IPN } \\
\text { Disponibilidade de mão de obra qualificada, } \\
\text { programas de apoio e promoção, proximidade } \\
\text { com universidades e centros de pesquisa e } \\
\text { infraestrutura. }\end{array}$ & $\begin{array}{l}\text { APL de Software de Curitiba/CENETIC } \\
\text { programas de apoio e promoção, } \\
\text { infraestrutura física e proximidade com } \\
\text { clientes. }\end{array}$ \\
\hline Debilidades & $\begin{array}{l}\text { Custo da mão de obra, falta de proximidade } \\
\text { com clientes, com produtores de } \\
\text { equipamentos, com fornecedores de insumos e } \\
\text { matéria-prima e indisponibilidade de serviços } \\
\text { técnicos especializados. }\end{array}$ & $\begin{array}{l}\text { Custo da mão de obra, incipiente } \\
\text { proximidade com universidades e centros de } \\
\text { pesquisa, indisponibilidade de serviços } \\
\text { técnicos, distância de fornecedores de } \\
\text { insumo e de produtores de equipamentos. }\end{array}$ \\
\hline $\begin{array}{l}\text { Importância das } \\
\text { Transações Comerciais } \\
\text { Locais }\end{array}$ & $\begin{array}{l}\text { Venda de produtos e/ou serviços (porém baixo } \\
\text { índice de relevância 0,37). }\end{array}$ & $\begin{array}{l}\text { Venda de produtos/serviços }(0,56) \text { e } \\
\text { aquisição de insumos de produção (0,58). }\end{array}$ \\
\hline
\end{tabular}

Fonte: Elaboração própria com base em pesquisa de campo (2015-2016).

Após o estudo do perfil das empresas entrevistadas e da estrutura e vantagens associadas ao ambiente local de cada polo, a próxima seção tem como objeto de estudo o processo de interação, cooperação e aprendizado que é propiciado por aglomerações de empresas, para posteriormente se adentrar

\subsection{INTERAÇÃO, COOPERAÇÃO E APRENDIZAGEM}

A interação entre empresas e instituições no desenvolvimento de atividades, produtos e processos é de grande relevância para o crescimento e desenvolvimento das diversas economias. Isso ocorre uma vez que permite a geração de sinergias para a transferência de conhecimento e tecnologia entre os diversos atores de um aglomerado, podendo levar à geração de inovações. O contexto local será, então, importante para a criação de diversas parcerias entre os agentes que visam à interação, à cooperação e à consequente transferência de conhecimento (BROWN; DUGUID, 2001). Diferentes contextos poderão ser mais ou menos indutores de aprendizagem por interação, de modo que os agentes, ao interagir e compartilhar conhecimento, são parte de uma cultura que dificilmente pode ser replicada com exatidão em outra localidade.

No que diz respeito às fontes de informação e aprendizado, Lemos (1999) afirma que o processo de geração de conhecimento e inovação implica no desenvolvimento de várias formas de aprendizado (learning). Dentre elas, é possível citar o learning-by-doing, que ocorre internamente às empresas e está relacionado com o desenvolvimento de capacitações científicas, tecnológicas e organizacionais. A esse respeito, as firmas entrevistadas tanto em Coimbra quanto em Curitiba afirmaram que a maior fonte interna é o departamento de P\&D. 
Além disso, devem-se ressaltar também as respostas em relação às fontes externas de informação para o aprendizado. O learning-by-interacting é caracterizado, segundo Lemos (1999), pela interação com fontes externas às firmas, como fornecedores de insumos, clientes, usuários, sócios, outras empresas, universidades e centros de pesquisa, instituições governamentais etc. A esse respeito, tem-se que a informação e o novo conhecimento externo, podem ser assimilados e aplicados a fins comerciais pelas firmas. Essa habilidade é chamada por Cohen e Levinthal (1990) de capacidade absortiva.

Em relação às principais fontes de aprendizado e novo conhecimento externo, algumas diferenças foram pronunciadas durante a pesquisa de campo nos dois casos estudados. Em Coimbra, as empresas citaram com maior frequência: os clientes $(0,45)$, centros de pesquisa e universidades $(0,37)$ e outras empresas dentro do IPN $(0,31)$. Já em Curitiba, clientes $(0,68)$, outras empresas do grupo $(0,60)$, associações empresariais $(0,57)$ e centros de capacitação privados, como o $\operatorname{SEBRAE}(0,52)$ foram os quesitos mais citados.

Analisando os resultados, no IPN, apesar dos clientes, dos centros de pesquisa e universidades e de outras empresas dentro desta instituição terem sido citados como principais fontes de informação para o aprendizado, deve-se ressaltar sua pouca expressividade para as empresas, devido a seu baixo valor atribuído. Das empresas entrevistadas, 12 afirmaram que os clientes são fontes importantes de aprendizado uma vez que levam em consideração as observações feitas por eles para realizar melhorias em seus produtos e serviços. Sete das empresas entrevistadas afirmaram que o IPN é o principal instituto que atua como fonte de informação para o aprendizado, sendo os laboratórios dessa instituição relevantes nesse quesito. Na sequência, os entrevistados citaram a Universidade de Coimbra e o Instituto Superior de Engenharia de Coimbra (ISEC) como fontes importantes de informação. Apesar de as respostas apresentarem índice de relevância baixo, $73,4 \%$ dos relacionamentos com universidades e $63,6 \%$ dos relacionamentos com centros de investigação são feitos com instituições que se localizam em Coimbra. Assim, destaque deve ser dado à Universidade de Coimbra e ao Instituto Superior de Engenharia de Coimbra.

Apesar disso, e levando em consideração os baixos índices de relevância para as fontes de informação e aprendizado, ressalta-se que o aprendizado por interação é de grande relevância para que o processo inovativo ocorra. Entretanto, é possível questionar se a aprendizagem apenas condicionada pela aglomeração territorial é um processo coletivo que penetra todo o sistema e dissemina o conhecimento (ASHEIM; EJERMO; RICKNE, 2011). Esse questionamento é plausível já que pode ocorrer distribuição desigual de aprendizagem e conhecimento devido à heterogeneidade das empresas. Essa heterogeneidade não pode ser totalmente compensada pela proximidade regional com universidades ou outras instituições.

Nota-se que tal fato pode ser apreendido no setor de TIC, já que é bastante heterogêneo, podendo perpassar todos os setores econômicos, o que dificulta que o processo de aprendizagem ocorra igualmente entre empresas pertencentes ao polo. Essa é uma questão peculiar e que pode ser verificada no polo de Coimbra, já que há uma grande diferenciação no que se refere à atuação e atividades desenvolvidas pelas empresas. Essa é uma característica não apenas da amostra, mas do todo dessa instituição. Assim, notou-se que, apesar da proximidade, o aprendizado ocorre de forma desigual entre as empresas, sendo mais difícil penetrar empresas com setores muito distintos.

Em Curitiba, os clientes, outras empresas do grupo, as associações empresariais e os centros de capacitação privados, como o SEBRAE, foram as principais fontes de informação para o aprendizado. A esse respeito, todas as empresas, em maior ou menor intensidade, citaram os clientes como importante fonte de informação, visto que a produção dos sistemas deve ser adaptada e, muitas vezes, customizada conforme a necessidade deles. Uma das empresas afirmou que "aprende a todo momento com os clientes e como tem informações dos clientes, sabe para onde ir para criar novos produtos". Outra empresa afirmou que a visão do cliente é fundamental no processo de aprendizagem, "pois é o cliente que usará o produto final". Notase a grande importância dos clientes uma vez que as empresas trabalham com o desenvolvimento de software para atender diferentes nichos e setores.

No que se refere às associações empresariais, no APL de Software de Curitiba, o CENETIC, a ASSESPRO, a REDE APL foram as instituições consideradas importantes como fontes de informação. Nesse quesito, algumas das empresas participaram da Missão ao Vale do Silício, nos Estados Unidos, promovida pelo APL de Software de Curitiba/CENETIC. Essa missão, para os que participaram, foi importante fonte de informação e aprendizado desde o processo até a forma de atuação. 
A troca de informação entre as empresas associadas ao CENETIC se mostrou relevante para algumas das empresas entrevistadas. A esse respeito, uma das empresas citou "A troca de informação sobre o processo de geração de boletos foi um exemplo importante que fez com que a empresa economizasse em seu processo". Uma das empresas entrevistadas afirmou que, para além das empresas do polo, empresas de outras localidades nacionais são importantes fontes de informação, sendo que a empresa em questão mantém contato para aprendizado com empresas que conhece por meio de congressos e seminários.

Além dessas questões, é preciso salientar a atuação do SEBRAE, instituição citada em menor ou maior grau por todos os entrevistados. De acordo com Comeli (2017), dentre as ações desenvolvidas pelo SEBRAE para o polo de Curitiba, deve-se ressaltar a disponibilização de espaço físico para a realização das reuniões mensais. Além disso, o SEBRAE atua apoiando e patrocinando a realização de eventos e contratação de palestrantes. Deve-se ressaltar também que o SEBRAE possui um projeto voltado para atender especificamente as empresas de TIC, o que contribuiu para que muitas empresas procurassem o CENETIC por intermédio do SEBRAE. Durante pesquisa de campo, a autora percebeu que o SEBRAE é a instituição que exerce maior peso em termos de informação e aprendizado.

Por outro lado, universidades e centros de pesquisa e investigação, não foram considerados grandes fontes de informação para o aprendizado. Com a pesquisa de campo, notou-se que o relacionamento com a UFPR, por exemplo, é deficitário e em grande medida não ocorre, principalmente por falta de interesse e visão muito acadêmica. Os interesses e a burocracia envolvida com o meio acadêmico da universidade federal acabam afastando o meio empresarial, principalmente em áreas tecnológicas como TIC, em que há mudanças a todo momento.

No que diz respeito à cooperação propriamente dita, no IPN, 77,8\% da amostra afirmou ter realizado algum tipo de atividade cooperativa entre os anos de 2012 e 2014. No APL de Software de Curitiba, a totalidade das empresas afirmou ter realizado alguma atividade cooperativa entre os anos de 2013 e 2015. Porém, deve-se verificar a relevância e o tipo de cooperação realizada pelas empresas, pois muitas delas não se destinam à geração de inovações propriamente ditas.

Em relação aos parceiros para cooperação entre os anos de 2010 e 2014, no IPN as empresas entrevistadas denotaram peso considerável tanto para Portugal quanto para a região de Coimbra. Como exemplo, dentre os entrevistados, um afirmou realizar cooperação com outras empresas nacionais que participam da incubadora da Energias de Portugal (EDP). Além disso, parceiros como a Universidade de Coimbra, o Hospital da Universidade de Coimbra, o Quadro de Referência Estratégico Nacional (QREN), a Universidade Nova de Lisboa, a Universidade do Minho e a Universidade do Porto foram citados durante entrevista. Em nível internacional, países como Inglaterra, França, Estados Unidos e Alemanha receberam maior destaque.

Quatro empresas afirmaram, durante entrevista, nunca ter desenvolvido atividades cooperativas com outras empresas ou instituições, mas que vislumbram futuramente, sendo esse um dos motivos que as levaram ao IPN. Três empresas fazem parcerias com "amigos pessoais", que são bons em determinadas áreas nas quais as empresas possuem debilidades. Essas parcerias, muitas vezes, ocorrem informalmente sem a elaboração de contrato e sem a realização de pagamento pelos serviços prestados. Ressalta-se também que uma empresa que trabalha com o desenvolvimento tecnológico de software foi beneficiada com um Fundo de Incentivo à Investigação em Portugal pelo QREN. Candidataram-se a uma forma de cooperação, com IPN, Universidade de Coimbra e Hospital da Universidade de Coimbra, sendo a empresa responsável pelo desenvolvimento tecnológico. Nessa rede, a empresa cuida da parte tecnológica do aplicativo que visa a alterar comportamentos com pequenas informações.

Já no polo de Curitiba, a totalidade das empresas entrevistadas afirmou desenvolver atividades em cooperação com outros agentes. Apesar disso, apenas as parcerias com órgãos de apoio e promoção apresentaram foram consideradas relevantes. Parcerias com outras empresas dentro do próprio polo, com outras empresas, clientes, universidades e institutos de pesquisa apresentaram um resultado inferior ao esperado quando se tem cooperação voltada para a inovação. Diferentemente do IPN, as empresas do APL de Software de Curitiba não relataram nenhuma parceria para cooperação com agentes do exterior, fato que pode estar relacionado à localização dos dois países.

A respeito das parcerias para cooperação, um dos entrevistados afirmou possuir parceria com outras empresas fora do arranjo com o intuito de gerar inovações tecnológicas. Outro entrevistado afirmou 
ter parceria com os Institutos LACTEC, outro com a American Chamber of Commerce for Brazil (AMCHAM), além do SEBRAE, empresas do polo, e o próprio APL de Software de Curitiba/CENETIC. Por outro lado, um dos entrevistados afirmou que "acha difícil a parceria para o desenvolvimento de produto". Segundo o entrevistado, isso ocorre até mesmo pelo conflito de interesses entre as partes.

No que tange à interação, cooperação e aprendizagem, as empresas também foram questionadas sobre as formas de cooperação realizadas. Em Coimbra, o desenvolvimento de produtos e processos apresentou maior índice de relevância $(0,64)$, segundo a Tabela 3 , reforçando a avaliação dos resultados das ações conjuntas realizadas: melhoria na qualidade dos produtos $(0,44)$ e desenvolvimento de novos produtos $(0,48)$ (Tabela 4). Em Curitiba, o desenvolvimento de produtos e processos e a cooperação para reivindicações foram os quesitos que apresentaram maior índice de relevância, 0,68 e 0,59, respectivamente (Tabela 3). Esse resultado também reforça a avaliação das ações conjuntas por parte das empresas: melhoria nos processos produtivos $(0,42)$ e novas oportunidades de negócios $(0,38)$, ressaltando os baixos valores apresentados nessa questão.

A esse respeito, em Coimbra, a maioria das empresas que busca parceria tem como objetivo o desenvolvimento de algum produto ou serviço, procurando empresas que possam cooperar em todo ou em parte do processo no qual possuem menor experiência. No que se refere aos resultados da cooperação entre as diversas empresas e instituições que nasceram dentro do IPN, é possível verificar, por exemplo, o desenvolvimento de um carrinho elétrico sem condutor. Esse carro foi desenvolvido dentro do instituto em parceria com uma empresa. Em seguida, a tecnologia foi transferida para uma spin off dentro do IPN e, posteriormente, foi transferida para um grupo, ao qual pertence uma das empresas incubadas do IPN.

Outra empresa dentro do IPN afirmou possuir parceiros, como outras empresas, instituições de financiamento (QREN), para o desenvolvimento de uma ponte articulada e um submarino conduzido externamente. Apesar de apresentar índice de relevância baixo, algumas das empresas afirmaram que a venda conjunta de produtos é uma importante forma de cooperação realizada. A esse respeito, uma das empresas entrevistadas, que trabalha com um aplicativo voltado para o turismo, afirmou possuir parceria com a ferramenta de busca Trip Advisor, realizando a venda conjunta de produtos e serviços.

Em Curitiba, por sua vez, a cooperação para o desenvolvimento de produtos e processos e as reivindicações apresentaram maior índice de relevância (TABELA 3). Um dos entrevistados citou a parceria com outras empresas para o desenvolvimento de software para drones, voltados para serviços especiais de segurança, saúde, reflorestamento e gestão de fiscalização ambiental. Como exemplo, para o projeto de desenvolvimento do software híbrido para a área de gestão ambiental, afirmou possuir parceria com os Institutos LACTEC.

Além disso, um segundo entrevistado afirmou que a empresa possui parceria com a Oracle, pois utilizam o software dessa empresa. Apesar disso, afirmou não possuir parcerias para o desenvolvimento de produto e que, quando essas parcerias já ocorreram, foram esporádicas e não relacionadas com o polo de TIC de Curitiba. Parcerias com o SEBRAE, por meio do SEBRAETEC diferenciação, também foram citadas e relevantes para a criação de projetos e financiamento para as empresas. Apesar desses resultados, a grande maioria das empresas entrevistadas, afirmou ser difícil a parceria para o desenvolvimento de produto, sendo mais comum ocorrer para o desenvolvimento de algum processo interno às empresas ou para a requisição de reivindicações.

TABELA 3 - IMPORTÂNCIA DAS FORMAS DE COOPERAÇÃO REALIZADAS

\begin{tabular}{l|c|c}
\hline \multirow{2}{*}{ Descrição } & IPN & APL de Software de Curitiba \\
\cline { 2 - 3 } & Índice de relevância & Índice de relevância \\
\hline Venda conjunta de produtos & 0,21 & 0,10 \\
\hline Desenvolvimento de produtos e processos & 0,64 & 0,68 \\
\hline Design e estilo de produtos & 0,16 & 0,33 \\
\hline Capacitação de Recursos Humanos & 0,09 & 0,10 \\
\hline Obtenção de financiamento & 0,18 & 0,13 \\
\hline Reivindicações & 0,00 & 0,59 \\
\hline Participação conjunta em feiras etc. & 0,03 & 0,13 \\
\hline Outras: especificar & 0,00 & 0,24 \\
\hline
\end{tabular}

Fonte: Elaboração própria com base em pesquisa de campo (2015-2016). 
No que diz respeito à avaliação dos resultados das ações conjuntas que já foram realizadas, todos os quesitos apresentaram índice de relevância inferior a 0,50 nos dois polos. Apesar de todos os itens apresentarem índice de relevância inferior a 0,50, a melhoria na qualidade dos produtos e o desenvolvimento de novos produtos foram os que se destacaram entre os entrevistados no IPN. Isso se deve ao fato de que as empresas, em sua maioria, quando buscam cooperação, o fazem tendo em vista o desenvolvimento de novos produtos e/ou serviços. Esses resultados são apresentados na Tabela 4. No APL de Software de Curitiba, a melhoria nos processos produtivos e novas oportunidades de negócios foram os resultados das ações conjuntas que se destacaram. A esse respeito, uma das empresas relatou que a realização de trabalhos em conjunto, apesar de não ter gerado o aumento de receitas, ajudou na divulgação e aprendizado, importantes tanto para o desenvolvimento de produto e/ou processo interno.

TABELA 4 - AVALIAÇÃO DOS RESULTADOS DAS AÇÕES CONJUNTAS JÁ REALIZADAS

\begin{tabular}{l|c|c}
\hline & IPN & $\begin{array}{c}\text { APL de Software de } \\
\text { Curitiba }\end{array}$ \\
\hline Descrição & Índice de relevância & Índice de relevância \\
\hline Melhoria na qualidade dos produtos & 0,44 & 0,20 \\
\hline Desenvolvimento de novos produtos & 0,48 & 0,30 \\
\hline Melhoria nos processos produtivos & 0,18 & 0,42 \\
\hline Melhoria nas condições de fornecimento dos produtos & 0,11 & 0,00 \\
\hline Melhor capacitação de Recursos Humanos & 0,05 & 0,07 \\
\hline Melhoria nas condições de comercialização & 0,14 & 0,13 \\
\hline Introdução de inovações organizacionais & 0,00 & 0,13 \\
\hline Novas oportunidades de negócios & 0,16 & 0,38 \\
\hline Promoção de nome/marca da empresa no mercado nacional & 0,05 & 0,10 \\
\hline Maior inserção da empresa no mercado externo & 0,10 & 0,00 \\
\hline
\end{tabular}

Fonte: Elaboração própria com base em pesquisa de campo (2015-2016).

Neste tópico foram desenvolvidas questões apreendidas durante pesquisa de campo nos dois polos em relação à interação, à cooperação e ao aprendizado. Ressalta-se que a interação entre empresas e instituições de apoio no desenvolvimento de atividades, produtos e processos é relevante para gerar formas de cooperação, aprendizado e inovação. A trajetória tecnológica será importante nesse aspecto, pois, levando em consideração essa trajetória, o histórico e a cultura local, regiões serão menos ou mais indutoras de aprendizagem e interação. Essa questão é relevante, inclusive, para afirmar que não é possível replicar com exatidão experiências de aglomerações de sucesso, como é o caso do Vale do Silício nos Estados Unidos.

O Quadro 3 apresenta uma síntese sobre as principais questões abordadas neste tópico. Por meio dele é possível perceber que a $\mathrm{P} \& \mathrm{D}$ interna às empresas é relevante para as duas realidades. Além disso, externamente, os clientes funcionam como importantes fontes de aprendizado, uma vez que o relacionamento com eles é indispensável para atender suas necessidades. Foi possível perceber também que, para as empresas do IPN, a Universidade de Coimbra desempenha papel importante, não apenas como fornecedora de mão de obra qualificada, mas também como parceira e fonte de aprendizado. Por outro lado, em Curitiba, as universidades e instituições de ensino não apresentaram grande relevância. Em parte, isso ocorre pelas diferenças de objetivos, mas se deve considerar também o recente histórico de políticas para aglomerações e de inovação no Brasil.

Quando o item resultados da cooperação é analisado, é possível reafirmar uma grande diferença entre os dois aglomerados. As empresas do IPN afirmaram que um dos resultados foi o desenvolvimento de novos produtos. Em contrapartida, as empresas do APL de Software de Curitiba tiveram como principais resultados a melhoria nos processos produtivos e novas oportunidades de negócios.

Assim, reforça-se a ideia de que a maioria das parcerias das empresas de Curitiba é voltada para o aprendizado e a resolução de problemas internos à firma, como uma melhoria no processo de produção. Por outro lado, em Coimbra, por também atender a demanda do mercado externo, muitas das parcerias são 
voltadas para o desenvolvimento de produto, seja para cobrir áreas em que a empresa não possui capacidade ou até mesmo no desenvolvimento conjunto de invenções. Essas diferenças podem estar relacionadas com o processo de constituição dos polos, seus objetivos quando criados, seus mercados e até mesmo as políticas governamentais implementadas em ambos os países.

QUADRO 3 - SÍNTESE DAS QUESTÕES RELACIONADAS A INTERAÇÃO, COOPERAÇÃO E APRENDIZAGEM

\begin{tabular}{|l|l|l|}
\hline & \multicolumn{1}{|c|}{ IPN } & \multicolumn{1}{|c|}{ APL de Software de Curitiba/CENETIC } \\
\hline $\begin{array}{l}\text { Fontes de Informação e } \\
\text { Aprendizado }\end{array}$ & $\begin{array}{l}\text { Departamento de P\&D, clientes, centros } \\
\text { de pesquisa e universidade, outras } \\
\text { empresas dentro do IPN. }\end{array}$ & $\begin{array}{l}\text { Departamento de P\&D, clientes, outras } \\
\text { empresas do grupo, associações empresariais e } \\
\text { centros de capacitação privados (SEBRAE). }\end{array}$ \\
\hline Cooperação & $77,8 \%$ sim & $100 \%$ sim \\
\hline Parcerias para cooperação & $\begin{array}{l}\text { Agentes Financeiros, IPN, Universidades } \\
\text { (Coimbra maior peso). }\end{array}$ & $\begin{array}{l}\text { SEBRAE, CENETIC, agentes financeiros, } \\
\text { outras empresas dentro do grupo. }\end{array}$ \\
\hline Formas de cooperação & $\begin{array}{l}\text { Desenvolvimento de produtos e } \\
\text { processos (ênfase em produtos). }\end{array}$ & $\begin{array}{l}\text { Desenvolvimento de produtos e processos } \\
\text { (ênfase em processos), cooperação para } \\
\text { reivindicações. }\end{array}$ \\
\hline $\begin{array}{l}\text { Avaliação dos resultados } \\
\text { das ações conjuntas }\end{array}$ & $\begin{array}{l}\text { Melhoria na qualidade dos produtos, } \\
\text { desenvolvimento de novos produtos. }\end{array}$ & $\begin{array}{l}\text { Melhoria nos processos produtivos e novas } \\
\text { oportunidades de negócios. }\end{array}$ \\
\hline
\end{tabular}
Fonte: Elaboração própria com base em pesquisa de campo (2015-2016).

No entanto, mesmo reconhecendo a necessidade do estreitamento das relações entre as universidades, empresas e demais instituições, sabe-se que em sistemas de inovação intermediários ou imaturos tais relações são débeis (SUZIGAN; ALBUQUERQUE, 2008). Isso ocorre, pois, mesmo em instituições de pesquisa e ensino consolidadas, há constrangimentos na mobilização de recursos humanos necessários para gerar expressivos circuitos de retroalimentação positiva entre as dimensões científicas e tecnológicas (RAPINI et al., 2009).

Desse modo, é fundamental que as universidades e os institutos de pesquisa presentes na região sejam capazes de dar suporte ao crescimento observado, a fim de que se formem bases sólidas e sustentáveis para o desenvolvimento regional. A excelência em capacitação tecnológica e científica das universidades, associada às demais instituições, pode constituir polos tecnológicos (VIEIRA; ALBUQUERQUE, 2007). Porém, para que isso ocorra, devem-se estreitar as relações de modo que, com o tempo, possam-se ter resultados positivos.

\section{CONCLUSÃO}

A partir da análise dos estudos de caso à luz da teoria das aglomerações de empresas, buscou-se identificar pontos positivos e negativos no funcionamento dos dois aglomerados, assinalando seus limites e potencialidades. Além disso, mostrou-se a relevância do planejamento de determinados apoios públicos a CT\&I na geração de inovações, principalmente no que se refere aos processos de interação e cooperação no surgimento de novas tecnologias, empresas e mercados. Para cumprir com o objetivo inicial, a análise das aglomerações de Coimbra e de Curitiba adentrou-se nas seguintes temáticas: estrutura e vantagens associadas ao ambiente local, interação, aprendizado e cooperação.

Durante o estudo, foi possível observar no IPN, assim como referido na revisão bibliográfica, um aparato institucional que interage e se relaciona. Dentre as principais instituições envolvidas na atuação do polo, cita-se o próprio instituto, a Universidade de Coimbra, o ISEC, as empresas associadas ao polo, outros polos de empresas em nível nacional e internacional, o governo português, a União Europeia, dentre outras. Assim, foi possível verificar os esforços para a criação de um aparato institucional para a requalificação da economia portuguesa, colocando a inovação como ponto central para o crescimento econômico. Ao que tudo indica, as redes de contato e parcerias são amplas e possuem força, contribuindo para o processo de geração de inovação de produto.

No APL de Software de Curitiba, observou-se que existe um esforço e um aparato institucional voltado para o apoio às empresas da aglomeração. Esse aparato envolve várias instituições, entretanto, as mais citadas pelas empresas foram a CENETIC e o SEBRAE. Apesar disso, a impressão é que o polo é 
sustentado pela colaboração espontânea que ocorre entre os associados, já que são estes os próprios governantes da aglomeração e CENETIC. Nota-se com a pesquisa de campo desse aglomerado que a maioria das parcerias é para resolver lacunas internas às empresas, bem como desenvolver inovações de processo nelas.

Os dados apresentados nesta pesquisa podem demonstrar o enraizamento local das atividades desenvolvidas pelas empresas de TIC do IPN. Além disso, ressalta a importância da Universidade de Coimbra na dinâmica desse polo. Apesar de grande parte da produção e serviço ser destinada ao mercado externo, devido ao tamanho do mercado português, as instituições existentes, mesmo que fracamente, desempenham papel importante para a sustentação e desenvolvimento do polo. Deste modo, podem ser consideradas relevantes e fator explicativo para a alta taxa de sobrevivência das empresas. Além disso, o objetivo de criação da aglomeração, bem como a necessidade das empresas em atender o mercado externo, podem ajudar a explicar a tendência em buscar parcerias interna ou externamente para o desenvolvimento de inovações de produto. Porém, deve-se ressaltar que apesar de verificar algum tipo de interação entre os atores envolvidos no polo, existe uma falta de cooperação entre as empresas associadas, que pode ser explicada, pelo curto tempo de vida das empresas.

Os dados aqui apresentados também sugerem que o enraizamento local das atividades desenvolvidas pelas empresas de TIC de Curitiba são incipientes. Apesar de universidades como PUC-PR e Universidade Positivo estarem no portfólio de apoios das instituições, elas foram pouco citadas no que se refere ao desenvolvimento conjunto de $\mathrm{P} \& \mathrm{D}$, aprendizado e interação. Para dar sustentação à afirmação de que o enraizamento local é incipiente nesse polo, ressalta-se a afirmação feita em entrevista por Comeli (2017):

[...] apesar de terem como meta tornar o Paraná uma referência no setor, em Curitiba, o que se observa é uma desmobilização, a partir do fim de 2016, em torno desta causa. Essa desmobilização ocorre em grande medida porque boa parte das empresas que participam do polo são voltadas para o desenvolvimento de Enterprise Resource Planning (ERP) que são softwares que integram os dados e processos de uma organização em um único sistema. Os softwares ERP têm perdido espaço no mercado, e assim, os empresários estão deixando de lado ações associativistas para focar em suas empresas propriamente ditas.

Por meio da análise das informações coletadas, percebeu-se que na aglomeração de TIC de Coimbra, na sua grande maioria, as empresas concentram seus esforços em inovações de produto. Por outro lado, em Curitiba, é dado destaque às inovações de processo. O que se conclui é que existem questões estruturais e de organização que determinam que em um polo se predomine a busca por inovações de produto e, em outro, inovações de processo.

A esse respeito, deve-se ressaltar algumas questões. Primeiro, o mercado principal das empresas dos dois aglomerados. Nesse quesito, ressalta-se que as empresas do IPN se caracterizam por serem em sua maioria start ups, por possuírem um pequeno mercado nacional e por estarem sujeitas à competição europeia, além do pequeno tamanho do mercado português. Essas questões corroboram para que as empresas foquem em inovações de produto, devido, inclusive, à competição externa. Em contrapartida, as empresas de Curitiba inovaram mais em processo. Esse fato pode estar relacionado à constituição um pouco mais antiga em relação às de Portugal e também à necessidade de atender o mercado nacional e local, principalmente em atividades de consultoria. Apesar disso, estão desenvolvendo projetos para promover a inovação de produtos e/ou serviços, o que pode ser resultado das recentes políticas industriais e de inovação. Ressalta-se apenas que esses projetos estão em fase de elaboração, não possuindo resultados até o momento.

Deve-se ressaltar também que a governança e o perfil dos empresários envolvidos atuam estimulando ou não a cooperação e a interação. No caso do APL de Software de Curitiba, o que se percebeu foi uma falta de governança sólida, já que a governança em si até existe, porém perde força a cada troca de gestores. Deste modo, é possível afirmar que o desenho institucional do sistema de inovação vai influir diretamente no processo de interação, aprendizagem e inovação. Um sistema de inovação sólido, com instituições de apoio, instituições financeiras, governo e universidades vai impactar positivamente no aumento das sinergias e geração de inovações de produto. Assim, os contextos locais e institucionais 
mostraram-se fundamentais para ressaltar as diferenças dos dois casos estudados, além de condicionantes estruturais, como a influência da União Europeia na atuação do polo português.

Recomenda-se que trabalhos futuros continuem a estudar a evolução de aglomerações em países menos desenvolvidos, ressaltando questões como o financiamento e o papel dos diversos atores no sistema de inovação, sobretudo o papel do governo e das universidades.

\section{REFERÊNCIAS BIBLIOGRÁFICAS}

ASHEIM, B. T.; EJERMO, O. E.; RICKNE, A. When is Regional "Beautiful"? Hoboken: Routledge Taylor \& Francis Group. 2011.

BROWN, J. S.; DUGUID, P. Knowledge and Organization: A Social-Practice Perspective. Organization Science, v.12(2), p. 198-213, 2001.

CAMPOS, R. R. et al. Aprendizagem por interação: pequenas empresas em sistemas produtivos e inovativos locais. In: LASTRES, H. M. M.; CASSIOLATO, J. E.; MACIEL, M. L. Pequena empresa: cooperação e desenvolvimento local. Rio de Janeiro: Relume Dumará Editora, 2004. p. 51-65.

CASSIOLATO, J. E.; LASTRES, H. M. M. O foco em arranjos produtivos e inovativos locais de micro e pequenas empresas. In: LASTRES, H. M. M.; CASSIOLATO, J. E.; MACIEL, M. L. Pequena empresa: cooperação e desenvolvimento local. Relume Dumará Editora. 2004. 21-33 p.

CASSIOLATO, J. E.; LASTRES, H. M. M.; STALLIVIERI, F. Introdução: Políticas estaduais e mobilização de atores políticos em arranjos produtivos e inovativos locais. In: CASSIOLATO, J. E.; LASTRES, H. M.M.; STALLIVIERI, F. Arranjos Produtivos Locais: Uma alternativa para o desenvolvimento. Experiências de Políticas. Editora E-Papers. Volume 2. 2009. 11-38 p.

COHEN, W. M.; LEVINTHAL, D. A. Absorptive Capacity: A New Perspective on Learning and Innovation. Administrative Science Quarterly, v. 35, n.1, p.128-152, mar. 1990.

COMELI, L. G. Entrevista concedida à doutorando. Consultor SEBRAE - Gestor do projeto APL de Software de Curitiba e Região, 2017.

HUGHES, T. P. Networks of Power. Eletrification in Western Society, 1880-1930. Baltimore: The John Hopkins University Press, 1983.

LEMOS, C. Inovação na Era do Conhecimento. In: LASTRES, H.; ALBAGLI, S. Informação e Globalização na Era do Conhecimento. Editora Campus, 1999.

RAPINI, M. S. et al. A contribuição das universidades e institutos de pesquisa para o sistema de inovação brasileira. In: XXXVII Encontro Nacional de Economia, 2009.

MESSERSCHMITT, DG; SZYPERSKI, C. Software Ecosystem : Understanding an Indispensable Technology and Industry. Cambridge, Mass : The MIT Press, 2003. ISBN: 9780262134323.

SAMPAIO, S. E. K. O desenvolvimento da aglomeração produtiva de software de curitiba. Dissertação. Programa de Pós-Graduação em Desenvolvimento Econômico da Universidade Federal do Paraná. 2006.

SANTOS, F.; CROCCO, M.; LEMOS, M. B. Arranjos e sistemas produtivos locais em "espaços industriais" periféricos: estudo comparativo de dois casos brasileiros. CEDEPLAR/FACE/UFMG, 2002. Disponível em: <http://www.cedeplar.ufmg.br/pesquisas/td/TD\%20182.pdf>. Acesso em: 20 fev. 2017. 
SERVIÇO BRASILEIRO DE APOIO ÀS MICRO E PEQUENAS EMPRESAS - SEBRAE.

Sobrevivência das Empresas no Brasil - Coleção Estudos e Pesquisas. 2013. Disponível em:

<http://www.sebrae.com.br/Sebrae/Portal\%20Sebrae/Anexos/Sobrevivencia_das_empresas_no_Brasil=2 013.pdf>. Acesso em: 26 ago. 2016.

SUZIGAN, W.; ALBUQUERQUE, E. M. A interação entre universidades e empresas em perspectiva histórica no Brasil. Texto para discussão, UFMG/Cedeplar, 329, 2008.

VIEIRA, K. P.; ALBUQUERQUE, E. M. O financiamento às atividades inovativas na região nordeste: uma análise descritiva a partir dos dados da Pintec. Revista Econômica do Nordeste v. 38(3), 2007. 